Article

\title{
An Analysis on the NASDAQ's Potential for Sustainable Investment Practices during the Financial Shock from COVID-19
}

\author{
Rachel Shields ${ }^{1}$, Samer Ajour El Zein ${ }^{2, *}$ and Neus Vila Brunet ${ }^{3, *}$ \\ 1 Research Center, Geneva Business School, Rue de, La Voie-Creuse 16, 1202 Genève, Switzerland; \\ rshields@gbsge.com \\ 2 Economics and Finance Department, EAE Business School, Calle d'Aragó, 55, 08015 Barcelona, Spain \\ 3 Faculty of Economics and Social Sciences, Universitat Internacional de Catalunya, Calle de Immaculada, 22, \\ 08017 Barcelona, Spain \\ * Correspondence: sajour@eae.es (S.A.E.Z.); nvila@uic.es (N.V.B.)
}

Citation: Shields, R.; Ajour El Zein, S.; Vila Brunet, N. An Analysis on the NASDAQ's Potential for Sustainable Investment Practices during the Financial Shock from COVID-19. Sustainability 2021, 13, 3748. https://doi.org/10.3390/su13073748

Academic Editor: Adam Zaremba

Received: 14 February 2021

Accepted: 22 March 2021

Published: 27 March 2021

Publisher's Note: MDPI stays neutral with regard to jurisdictional claims in published maps and institutional affiliations.

Copyright: (C) 2021 by the authors. Licensee MDPI, Basel, Switzerland. This article is an open access article distributed under the terms and conditions of the Creative Commons Attribution (CC BY) license (https:// creativecommons.org/licenses/by/ $4.0 /)$.

\begin{abstract}
There is a growing demand for sustainable business practices and for sustainable and impact investment as has been signaled by the Sustainable Development Goals ratified by all the United Nations members. However, there is not that much evidence on how sustainable investments perform during crises compared to regular investments. This paper investigates if sustainable investments within the NASDAQ have a lower volatility rate when reacting to a significant global crisis such as the COVID-19 pandemic. It groups the shares of businesses with Corporate Social Responsibility (CSR) practices that are ranked 70\% or higher given by CSRHub, Inc. and compares it to business shares with the lowest-ranked CSR business practices at 30\% or lower. The top 30\% and bottom $30 \%$ CSR stocks' volatility will be predicted using variations of the GARCH model. The top $30 \%$ CSR stocks of the NASDAQ had a lower rate of volatility for a global crisis than the bottom $30 \%$ CSR stocks. Technology is the only sector whose top 30\% showed higher volatility. However, the top $30 \%$ of companies in the Health Care and Utilities sectors show a higher increase in returns and a lower drop in returns. These results signal the higher uncertainty associated with some cutting-edge products and services offered by the top 30\% of technology companies and the preference for more established companies that offer higher quality services when it comes to satisfying basic needs such as health and utilities in difficult times.
\end{abstract}

Keywords: GARCH; NASDAQ; Corporate Social Responsibility; sustainable investments

\section{Introduction}

A global pandemic has brought new meaning to risk in the modern world of investing. COVID-19 [1], also known as SARS-Cov-2, was declared a global pandemic [2], on March 11th, 2020, by the World Health Organization [3] (p. 157). The growth of the virus from an epidemic to a pandemic created an economic "snowball effect". Most countries were not prepared for the spread of COVID-19, which was defined as a "super spread" based on the outbreak's rapid pace [4] (p. A1). Due to the unexpected rise in cases and deaths, most governments moved to lock down their nations and establish a quarantine. As a result, industries in many different sectors suffered from either a supply shock or a demand shock. These shocks, historically low interest rates, and many other factors led economists to speculate that there would be a global recession due to the pandemic [5]. These economic speculations were reflected in the market as extreme market uncertainty and volatility. During a worldwide pandemic, where should investments shift? Are there financial benefits, as well as ethical benefits to investing sustainably?

Investing in the stock market has adapted from a primary focus on monetary returns into a focus on sustainability. There are multiple ways to define a sustainable investment. 
Ultimately, sustainable investing creates a positive social and environmental impact [6]. In most literature sustainable stocks are defined as Environmental Social and Governance (ESG) stocks. For the purpose of this paper, sustainable stocks are defined as the top 30\% Corporate Social Responsibility (CSR) ranking. The CSR ranking is based on how well businesses handle "sustainable issues" [1], in order to make a more positive social and environmental impact. The higher the CSR ranking is for that company, the more the shares for that company are considered sustainable.

Businesses' commitments to CSR have expanded since 2015 when all the United Nations member nations signed the 2030 Agenda for Sustainable Development and governments allocated a substantial portion of their budgets in promoting sustainable practices in all the seventeen goals identified. The concept of sustainable development from the economic and business perspective is encompassed in the Sustainable Development Goals number eight and twelve. These goals promote "sustained, inclusive and sustainable economic growth, full and productive employment and decent work for all", and "sustainable consumption and production patterns" [7] (United Nations, 2021). Hence, there is a higher demand for sustainable stocks coming from governments, private investors as well as citizens.

An increase in demand for sustainable assets does not mean investors are not interested in gaining monetary returns, but in recent years the definition of return on investment has changed [8]. The value of a stock also includes the sustainable practices that the company is implementing. Through investing in companies that are socially and environmentally responsible, it is possible to reduce the probability of a crisis, like COVID-19, that is brought on by a zoonotic virus [9]. Limiting companies' environmental impact could reduce the exposure of further zoonotic viruses and avoid a major pandemic in the future, as just one example of how investing in CSR companies is financially beneficial in the long term.

Since Corporate Social Responsibility is still a developing business practice, there are many different ways to measure sustainability. For the purpose of this analysis, the standards of sustainable stocks will be defined based on company rankings from CSRHub, Inc. It is a certified B corporation, which means the company's business practices are legally focused on "a balance of profit and purpose" [10]. CSRHub, Inc. ranks companies' Corporate Social Responsibility practices based on twelve subcategories. These subcategories include community, employees, environment, and governance [1]. Based on these subcategories, each company received an overall rating and a percentile ranking compared to the other companies.

This paper analyzes the volatility of the NASDAQ during COVID-19 to compare the performance of CSR-ranked stocks. The literary review reflects articles written about the financial crisis from COVID-19 and the potential of sustainable investing. In the methodology, the stocks ranked a the top $30 \%$ or higher, according to CSRHub, Inc., are compared to the stocks ranked at the bottom $30 \%$ for sustainable practices. The hypothesis is that the top-ranked CSR stocks will outperform the bottom-ranked stocks due to investors certainty in the long-term financial and sustainable benefits of CSR stocks. Comparing the volatility between the two categories will determine if the highly ranked CSR stocks perform better and have less volatility brought on by the shock of COVID-19. Using the GARCH (Generalized AutoRegressive Conditional Heteroskedasticity) method [2], this paper compares the spikes of volatility through the returns' conditional variance. The top $30 \%$ of CSR stocks in the NASDAQ have a slightly lower initial spike from the global pandemic than the bottom $30 \%$ of CSR stocks. The majority of the sectors reflect the same results with few exceptions.

\section{Literature Review}

\subsection{COVID-19 Financial Crisis}

The long-term financial effects of COVID-19 are almost impossible to predict with complete certainty. However, understanding the trends in volatility and uncertainty over 
the course of the pandemic creates a better understanding of the potential volatility in the short-term future and medium-term futures. Many different factors can cause volatility in the market. On a macro level, one of the most significant correlations is between market volatility and political uncertainty. Guo and Mei [11] tested nine different political atmospheres and found that eight out of nine have a significant positive correlation. When there is an uncertain change in politics, either a change in regulation or an upcoming election, there is a jump in market volatility. Investors are faced with the uncertainty of how new regulations and government policies brought on by the pandemic will affect a business's cash flows.

The correlation between uncertainty and market volatility stems from investor biases. Behavioral finance helps explain market biases that lead to increased volatility. One of the market biases explained by behavioral finance is overconfidence or under-confidence in the market. An overconfident investor will overestimate the probability of a good outcome in the market, which leads to higher risks. An under-confident investor will underestimate a good outcome in the market. This pessimism leads to risk aversion. This can lead to investors dumping their shares [12] (p. 12). COVID-19 was an unpredictable event, causing investors to lose confidence in the market.

After comparing different factors, Baker et al. [13] observed that mortality rates and supply chain shocks do not have nearly as significant an impact on the stock market as government closures and quarantine regulations. They use 16 categories to explain each one of the 1134 jumps of over $2.5 \%$ in the market since 1900 by analyzing the relevant newspapers during the jump. This method shows COVID-19 has the highest number of negative and positive jumps in all categories and is the only pandemic to create jumps primarily from government policies and quarantine.

Also, the financial impact will be significant across the globe. Since COVID-19 is a survivable event, compared to something like a nuclear war [14] (p. 3), there is an important emphasis on the financial market. Companies are facing a drop in financial flexibility. While companies that are already prepared for disasters tend to be less levered already. COVID-19 has become a catalyst for changes in business practices and financial strategies for companies.

Optimistic beliefs in regards to CSR businesses seem to have the opposite effect on risk. First, there is a positive correlation between CSR business practices and the business's performance [15]. Adding to this analysis, they have also proven there is a negative correlation between CSR business practices and market risk in the European market. As the CSR business practices increase, there is a decrease in total market-based risk. The lower risk leads to investors being more confident in businesses with higher CSR performances. Unfortunately, at this time, there is limited research into the risk relationship and CSR businesses within the US market.

\subsection{The Potential of Sustainable Investing}

The pandemic's financial crisis is a catalyst to advocate the need for the financial and economic benefits of sustainable investing. There is a growing demand for sustainable practices to reduce the potential future crises. According to Dr. Koundouri [9], there have been many crises that the current generation has faced, including the Great Recession, climate crisis, and COVID-19. These crises should not be met with the same socio-economic policies. Instead, there should be an emphasis to focus on sustainable policies that would reduce the effects of another future crisis. Her argument uses the examples that the deforestation of certain areas has the potential to lead to more "zoonotic viruses" [9] (p. 2), which is only one example of the consequences of lack of sustainable practices.

COVID-19 gives the private and public sectors the unique perspective that there are too many consequences to going back to the way the world was before the pandemic. Some of the "physical shocks" [16] from the pandemic include unprepared health organizations and businesses failing. The lack of investments to reduce the risk of those physical shocks also contributed to the magnitude of the crisis. Reallocating investments to sustainable 
practices creates the opportunity to avoid unexpected disasters, or at least marginally improve the risk related to future crises.

These economic implications have become apparent on a global level and government regulations are shifting to include sustainability. As previously mentioned, [11], regulations will affect the market and cannot be ignored by investors. The United Nations Global Compact is a list of sustainable development goals to be reached by 2030. The 17 Sustainable Development Goals (SDGs) set a standard for businesses to improve civil rights, decrease carbon footprints, and increase the responsible collaborations between institutions [7] (UNGC, 2020). There are over 160 countries that have pledged to uphold the SDGs through improvements in government regulations, including the US [7] (UNGC, 2020).

The US Securities and Exchanges Commission (SEC) has taken steps towards sustainable practices. The SEC has been discussing adding Sustainability Discussion and Analysis, also known as SD\&A [17], to the commission disclosure framework. According to Fleming and Ledbetter [18], both investor advocates for the SEC, the process to set a standard will be slow due to the differences in business types and the current sustainable standing of each business. However, the market is moving in a direction towards sustainability and major market investors, like Black Rock [17], are interested in sustainable transparency. The SEC has created a task force from the International Business Council of the World Economic Forum that is working to create sustainable metrics.

\subsection{Sustainable Stock Performances}

In the model of a perfect world, the factors of sustainable businesses are straightforward and easily defined, as shown in the UN Global Compact [19]. However, real-world business practices are not as easily defined, as shown with the potential motivations of a business's strategy by Burritt and Schaltegger [20]. The real world seldom fits an exact model. The increased awareness of CSR business practices has led to many different ways of rating a company's sustainability practices. Most investment firms have created their own list of standards a company must reach to be considered sustainable. For example, KPMG (Klynveld Peat Marwick Geordeler), NRI (Networked Readiness Index), and PwC (Price Waterhouse and Coopers \& Lybrand) each have their own list of "sustainability indicators" [21]. It is impossible to determine what institution has the most accurate list of standards. However, a system that pulls together many different verified ratings to create an aggregate ranking system narrows down inaccuracy potential.

CSRHub, Inc. is a corporation that pulls together the sustainable ratings of 17,505 companies based on the information provided by 715 different viable sources [1]. CSRHub, Inc. uses the combined ratings to create more consistency in comparing companies. Aggarwal [22] (p. 3) was able to use the specific rankings within CSRHub to determine if there is a correlation between the improvement of corporate governance and corporate financial performance. Companies come in all different shapes and sizes. The cash flow dedicated to sustainable business practices may seem significantly larger compared to another company. However, the latter company may be a smaller company than the former. Many smaller details have to be taken into consideration before distributing the CSR rankings [1]. These determinants are further explained in the methodology section. CSRHub, Inc. is a tool that allows researchers or investors to analyze further financial performance based on sustainable practices.

Determining the risk beta on sustainable stocks has slowly progressed. According to Alessandrini and Jondeau [23], it is possible to filter an investment portfolio to only include high-ranking sustainable investments and still receive returns with a relatively accurate risk beta. There are some important factors to consider when determining the beta. In their sample of testing, filtering for only high-ranked sustainable loans reduced the amount of medium to small-sized businesses within the portfolio. The large companies have more resources available to improve their sustainability practices and therefore, are ranked higher on the sustainable scale. There may be building biases that need to be further tested as sustainable stock develops on the risk beta for sustainable stocks that 
are now being considered common knowledge. For example, according to their results, European companies may be favored over United States companies to hit the standards for sustainable stocks. Also, information technology will outweigh sectors like finance and Energy as less risky sustainable investments [23] (p. 22). Ultimately, there needs to be further testing of the risk beta in terms of a socially responsible investment portfolio.

COVID-19 has affected the entire world. While there is literature about market certainty pertaining to sustainable stocks in the European markets, there is limited testing in US markets. There is some testing on the performance of sustainable stocks in the US market. The majority mainly focus on the performance of the companies. There is little proof showing investor biases towards high-ranked CSR stocks in the US market. These biases can reflect the risk of high-ranked CSR stocks. It is still undetermined whether investors have higher confidence in high-ranked CSR stocks and less uncertainty leading to lower volatility in high-ranked CSR stocks within the US market [24]. There are even fewer research papers on the certainty of high-ranked CSR stocks during a financial crisis, especially one brought on by an unpredictable pandemic that has affected business practices on a global scale. The fact that every business has been affected by the pandemic and adapted their practices in order to stay in business provides an opening for them to improve their CSR business practices.

\section{Materials and Methods}

This section of the paper introduces the methodology of the analysis. The data are collected from multiple resources. One of the resources is the daily rate of change on stock prices within the NASDAQ. This information is uploaded from the closing prices of the NASDAQ on Yahoo Finance [25] and downloaded onto Stata. Stata is a programming tool used for econometric analysis and financial forecasting. The daily rate of changes in the NASDAQ provided by Yahoo Finance is then sectioned out using the sustainability rankings provided by CSRHub, Inc. [5]. These rankings provided by CSRHub, Inc. are explained in detail below. The top 30\% of CSR stocks will be compared to the bottom $30 \%$ of CSR stocks to determine which groupings have lower volatility leading to higher investor confidence. It will also determine which grouping performs better during a financial crisis brought on by an unexpected global event. In order to test the data for volatility, a popular time series econometric method for testing volatility called the GARCH method [9] will be used. This method stems from the ARCH (AutoRegressive Conditional Heteroskedasticity) method [26]. In order to fully understand the analysis of GARCH, it is first necessary to understand the ARCH model. There are multiple versions of GARCH. In order to show a broader perspective, the CSR stocks will be tested by GARCH and EGARCH (Exponential AutoRegressive Conditional Heteroskedasticity) to determine which statistical parameters will be more accurate for a full analysis. The methodology will build up an explanation of the basics of econometrics, leading up to time series econometrics. It will follow with an explanation of $\mathrm{ARCH}$, the improvement of the model to $\mathrm{GARCH}$, and then finally explain the differences between GARCH and EGARCH.

\subsection{Data Collection}

The NASDAQ Composite is a major stock exchange. It has over 2800 companies listed on its market and about $\$ 12$ trillion being traded [27]. Historically, the NASDAQ has been a more volatile market than most of the major markets. If this market is considered volatile in normal economic circumstances, testing the marginal increase in volatility is a good indicator of market certainty. The historic volatility of the NASDAQ is due to the fact that the market is considered a growth market. Many of the companies posting IPOs (Initial Public Offerings) on the NASDAQ are new companies with the potential to grow [28]. Since the NASDAQ is a growth market, part of that growth should be testing out the trends of the sustainable practices growing businesses are using.

The NASDAQ has also been adapting to the global sustainable initiative. There are some listed companies that follow the principles of the UN Global Compact (UNGC). The 
UN Global Compact, as previously mentioned, invites companies to align their business practice goals with the UNGC to improve human rights, labor, the environment, and limit corruption [20]. However, there are limitations to the reporting companies provide. Those companies have the ability to label themselves sustainable to create better branding while only minimally improving their business practices [29]. There are limitations to the number of checks and balances within this type of reporting. The NASDAQ also has its own ESG guideline for sustainable business practices. This guide also has its limitations of information about the overall sustainable practices of the market. It is used primarily as a support for the Nordic and Baltic markets, but has limited information on the sustainability practices of the NASDAQ Composite.

As previously mentioned, for the purpose of this analysis, company rankings for CSRHub, Inc. will be used to define the terms of sustainable investment. CSRHub, Inc. is a B-certified corporation that is dedicated to sharing sustainable data for investors and academic research. The B certification indicates that the company is legally obligated to have business practices that are an equal combination of for-profit practices, as well as sustainable practices. The data the company collects are primarily used for investors looking to trade sustainable or research projects on sustainability.

Our analysis is based on the data provided by CSRHub, Inc. [5]. CSRHub, Inc. [5] explains in its methodology section that the sources of data that they use each have their own rating and measurement methodology, and that most of the sources only offer a relative rating such as "top 50" or "top 30", or "best performing", and "lower 50", or "lower 30", or "worst performing". CSRHub, Inc. [5] has converted all the data into a numeric scale from 0 to 100 and has normalized the data. Given the nature of the data from CSRHub, Inc. [5] and the classification of top 30\% (high), middle 40\% (medium), and bottom 30\% (low), used in the seminal work of Fama and French (1995) about the size and book-to-market factors in earnings and returns, we based our study on Fama and French's (1995) [30] classification of high and low. Hence, the rankings above $30 \%$ are grouped into the highest category for CSR business practices, and the bottom 30\% rankings are grouped into the lowest category for CSR business practices. This analysis will compare the top $30 \%$ with the bottom $30 \%$. These rankings of the top $30 \%$ and the bottom $30 \%$ of ranked CSR stocks in the NASDAQ will be used to compare the volatility between the two groups within each sector.

CSRHub, Inc. uses information from multiple sources in order to provide rankings. These sources include, but are not limited to, "ESG analysis firms, Non-Governmental Organizations (NGOs) such as foundations, associations, union groups, and activist groups, government databases, publications and research reports" [5]. Collecting information from multiple sources allows the company to have a robust understanding of the sustainable practices for each company ranked. If there is insufficient verified information on a company's sustainable business practices, the company receives a "N/A" rather than a numeric ranking. Since the rankings are based on multiple resources grouped together to create the ranking, it solves the issue previously mentioned. The multiple resources are used as a checks and balances system that allows a more transparent review of the companies. CSRHub, Inc. [5] explains in its methodology section that it trims its data when there is not enough information. They report that they had to drop 140,000 companies since they were not able to provide all the required data in order to obtain a CSR score. The sectors with the lowest CSR scores are Energy, Basic Materials, and Utilities.

CSRHub, Inc. has two main ratings and twelve subcategories. The first main rating is considered the "absolute rating", where sustainable business practices are rated as an absolute value between $0-100$. The second rating is a percentile ranking, where the overall performance of the company is compared to the performance rating of all other rated companies. A company with a higher percentage ranking is considered in the upper percentile of sustainable business practices. The overall rankings are based on twelve subcategories that are grouped into four main subcategories. The first main subcategory is community, which includes development and philanthropy, human rights and supply 
chain, and product. The second is employee compensation and benefits, which include diversity and labor rights, training, and health and safety. The third main subcategory is environment, which includes energy and climate change, environmental policy and reporting, and resource management. Finally, the fourth main subcategory is governance, which includes board and leadership ethics and transparency and reporting.

\subsection{GARCH}

The purpose of this paper is to identify the areas in the markets where there is less uncertainty in CSR stocks during a financial crisis, which was brought about by the global pandemic. Uncertainty can be determined by the volatility of the market. Liu and Zhang [31] have shown that economic policy uncertainty leads to significant jumps in market volatility. There is a significant correlation between market volatility and uncertainty. In order to test and compare the marginal uncertainty of each sector in the NASDAQ, it is necessary to use the GARCH model over other models, like the French Fama Five-Factor method. The French Fama Five-Factor method is more focused on market returns, whereas the GARCH method measures market volatility [32]. The outcome of market volatility, using the GARCH method, will further determine which sectors have CSR stocks that have less volatility and, therefore, more investor certainty.

Before going into detail about the GARCH model, it is important to have an understanding of the application of the autoregressive model (AR) and ARCH models and how they pertain to this hypothesis. The GARCH model builds on first the ARCH model to create a more accurate depiction of market volatility. The autoregressive model, also known as the AR model, captures the white noise variable previously mentioned. This would be the standard error that does not account for changes in independent variables. Specifically, using an AR model with a time lag of one:

$$
X_{t}=\beta X_{t-1}+e_{t},
$$

where $X$ is considered a random error that is regressed on itself at the first lag, the value of $X$ is determined based on the lagged previous period of that variable with a random standardized error. The variance of this time series is limited to $V\left(e_{t}\right)=1$, while the mean is 0 [33] (p. 15). Typically, the AR model is part of the ARMA model, or Autoregressive Moving Average model.

This model does not include the heteroskedasticity of real-world independent financial variables. The ARMA model is used with the basis that the variance is constant. A constant variance does not see fluctuations in the amount of variance over time. This makes the ARMA model impossible to use for accurately evaluating the volatility of the market [26]. Since the market can have periods of high volatility, then swiftly change to low volatility, the variance cannot be considered constant over time. Volatility does not stay at the same rate in the short-term or long-term market. The real market fluctuations are considered heteroskedastic. In terms of finance, Conditional Heteroskedasticity is used. Conditional Heteroskedasticity and conditional variance are almost synonymous with each other.

The GARCH(p,q) model is often analyzed as the GARCH $(1,1)$. This model takes the initial ARCH(p) model, which calculates a certain number of periods of the autoregression and adds the (q). This variable can be considered the moving average of a certain number of periods of high-intensity volatility during the pandemic. This model primarily focuses on improving the calculations of the variance [32]. Lagged variance is added to the initial ARCH equation in order to make it a GARCH equation.

Where the $\mathrm{ARCH}$ variation is:

$$
\sigma^{2}{ }_{t}=\alpha_{0}+\alpha_{1} \varepsilon^{2}{ }_{t-1}
$$

The GARCH adds lagged variance:

$$
\sigma^{2}{ }_{t}=\alpha_{0}+\alpha_{1} \varepsilon^{2}{ }_{t-1}+\gamma \sigma^{2}{ }_{t-1}
$$


The lagged variation allows an infinite process in variation [32] (p. 229). According to Hansen and Lunde [34], this basic GARCH $(p, q)$ model is accurate in using the volatility of the market to predict future volatility. The two economists tested over 300 volatility models, some that were considered more advanced than $\operatorname{GARCH}(\mathrm{p}, \mathrm{q})$, and determined the models that were considered more advanced did not outperform the forecasting of the $\operatorname{GARCH}(\mathrm{p}, \mathrm{q})$ model.

The asymmetric model, EGARCH, provides a different perspective on forecasting market volatility. In finance, new events and information can create a rapid rise in volatility, but the reduction of volatility usually lowers at a slower rate than the initial rise. Asymmetric GARCH methods account for the asymmetry in the rates of change in the volatility [32] (p. 250). Specifically, the EGARCH method, also known as the Exponential GARCH, changes the standard variance to the natural logarithm. In order to see a comparison between GARCH and EGARCH, the variance equation from GARCH is shown below:

$$
\sigma^{2}{ }_{t}=\alpha_{0}+\alpha_{i} \varepsilon^{2}{ }_{t-i}+\gamma \sigma^{2}{ }_{t-i},
$$

While the mean portion of the full equation never changes, the standard variance of the EGARCH equation is the logarithm of itself:

$$
\ln \left(\sigma^{2}{ }_{t}\right)=\alpha_{0}+\sum_{i=1}^{p}\left(\alpha_{i 1}\left|\frac{u_{t-1}}{\sqrt{\sigma_{t-1}^{2}}}\right|+\alpha_{i 2} \frac{u_{t-1}}{\sqrt{\sigma_{t-1}^{2}}}\right)+\sum_{j=1}^{q} \gamma_{j} \ln \left(\sigma_{t-j}^{2}\right)
$$

where the standard error becomes a nonlinear response to unexpected news within the year 2020:

$$
\alpha_{i} \varepsilon^{2}{ }_{t-i}
$$

Which is replaced with:

$$
\alpha_{i 1}\left|\frac{u_{t-1}}{\sqrt{\sigma_{t-1}^{2}}}\right|+\alpha_{i 2} \frac{u_{t-1}}{\sqrt{\sigma_{t-1}^{2}}},
$$

First, the parameters are set such that, if $\varepsilon_{t}>0$, then the positive shocks have a higher rate of volatility compared to negative shocks. If $\varepsilon_{t}<0$, then the negative shocks are at a higher rate, and when $\varepsilon_{t}=0$, the model is symmetric. The conditional variance is now represented by $\alpha_{i 1}$ as a nonnegative standard and represents $\alpha_{i 2}$ the effect of the asymmetric condition. The increased complexity of the equation represents the phenomenon of differences in the rate of increased volatility within the NASDAQ.

\subsection{Assumptions}

The data will be analyzed using the following assumptions. As previously stated, there is not a significant relationship between market volatility and COVID-19 cases or deaths [15]. However, there seems to be a significant correlation between changes in government policies or political events and market volatility [12]. The volatility is a result of the uncertainty investors have when there are major events. The market returns of the top 30\% CSR stocks and bottom 30\% CSR stocks should provide a more robust analysis of the volatility outcome. The hypothesis being tested is that there is less volatility within high-ranking CSR stocks due to investor trust in those companies.

\section{Empirical Results}

Based on the hypothesis, the following section will first explain the results of the top and bottom $30 \%$ of CSR stocks in the NASDAQ as well as each sector, then go further into the analysis brought on by GARCH, and E-GARCH methodologies in order to determine the conditional variance. In order to understand the theory behind GARCH models, the ARCH model was first built by Robert Engle [35] (Engle, 1982) as a mechanism of 
estimating time-varying volatility. Moreover, the univariate GARCH is the most commonly accepted and robust model for estimating and forecasting the volatility of returns of an asset. The overall NASDAQ results will be described in detail, and the sectors will be represented with a numeric summary of the market performance and conditional variance. The conditional variance will represent the rate of volatility when there is a global crisis, such as COVID-19.

The percentile is ranked as a percent of the CSR category performances compared to the ratings of all other companies listed in CSRHub, Inc. The service provided by CSRHub, Inc. provides limited information on the CSR rankings, which excludes the companies that are not yet ranked [5]. The data categories show a significant difference in the number of stocks in the NASDAQ that are defined as top 30\% and bottom 30\% (Table 1). There are significantly more companies in the NASDAQ that have poorly rated sustainable business practices, showing a need for more companies to improve their practices. When broken down by sector, each sector has a higher number of stocks in the bottom 30 percentile, without exception.

Table 1. The number of companies listed in the top 30\% Corporate Social Responsibility (CSR) stocks and bottom 30\% CSR stocks for the NASDAQ and each sector.

\begin{tabular}{ccc}
\hline Sectors & CSR Grouping & Number of Stocks \\
\hline \multirow{2}{*}{ Overall NASDAQ } & Top 30\% CSR & 151 \\
& Bottom 30\% CSR & 692 \\
\hline \multirow{2}{*}{ Basic Materials } & Top 30\% CSR & 0 \\
& Bottom 30\% CSR & 14 \\
\hline \multirow{2}{*}{ Consumer Goods } & Top 30\% CSR & 19 \\
& Bottom 30\% CSR & 57 \\
\hline \multirow{2}{*}{ Consumer Services } & Top 30\% CSR & 6 \\
& Bottom 30\% CSR & 27 \\
\hline \multirow{2}{*}{ Financials } & Top 30\% CSR & 12 \\
& Bottom 30\% CSR & 194 \\
\hline \multirow{2}{*}{ Health Care } & Top 30\% CSR & 28 \\
\hline \multirow{2}{*}{ Industrials } & Bottom 30\% CSR & 188 \\
\hline \multirow{2}{*}{ Energy } & Top 30\% CSR & 13 \\
& Bottom 30\% CSR & 63 \\
\hline \multirow{2}{*}{ Technology } & Top 30\% CSR & 3 \\
\hline \multirow{2}{*}{ Telecommunications } & Bottom 30\% CSR & 25 \\
\hline \multirow{2}{*}{ Utilities } & Top 30\% CSR & 54 \\
& Bottom 30\% CSR & 85 \\
\hline & Top 30\% CSR & 12 \\
\hline & Bottom 30\% CSR & 31 \\
\hline \multirow{2}{*}{ Top 30\% CSR } & 4 \\
\hline
\end{tabular}

\subsection{The Overall NASDAQ}

The actual comparison of the volatility in the market can be seen in Figure 1c. This figure shows the volatility represented by the conditional variance of the GARCH model for the top 30\% CSR stocks and the EGARCH model for the bottom 30\% CSR stocks. As previously mentioned, the EGARCH model is used when there is asymmetric variance, which is shown in the graph. The volatility of the bottom $30 \%$ CSR stocks spike significantly higher than the top 30\%. The highest rate of volatility for the top 30\% CSR stocks reaches about 0.006 , and the highest rate for the bottom $30 \%$ CSR stocks reaches 0.1 . However, these jumps lessen as the pandemic continues, showing higher volatility in the top 30\% category around the time of the second phase of COVID-19 in September. There is a 
significant positive correlation between volatilities at $92 \%$. So, the two volatilities seem to have relatively the same reaction to the pandemic. The only major difference being the initial spike at the beginning of the pandemic [36-40].

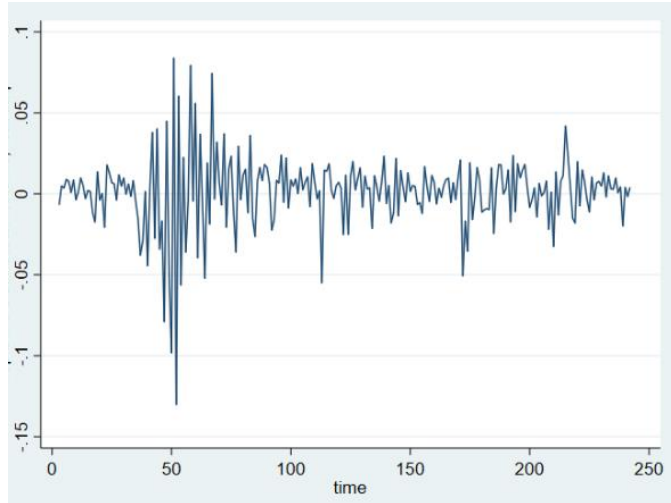

Top 30\% CSR Stock Returns, NASDAQ

(a)

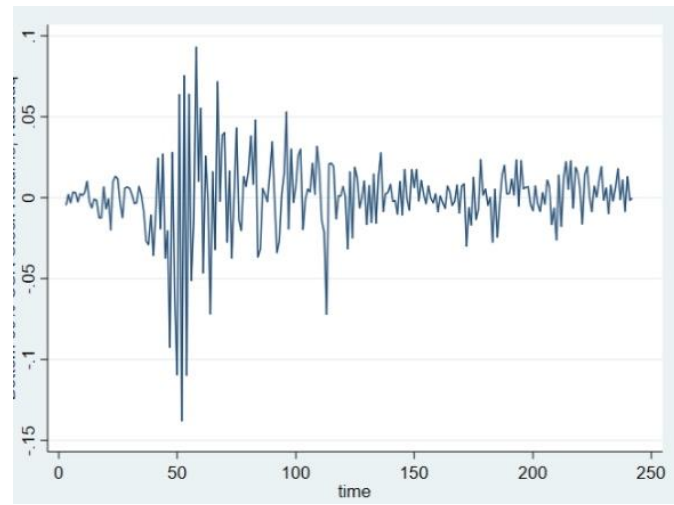

Bottom 30\% CSR Stock Returns, NASDAQ

(b)

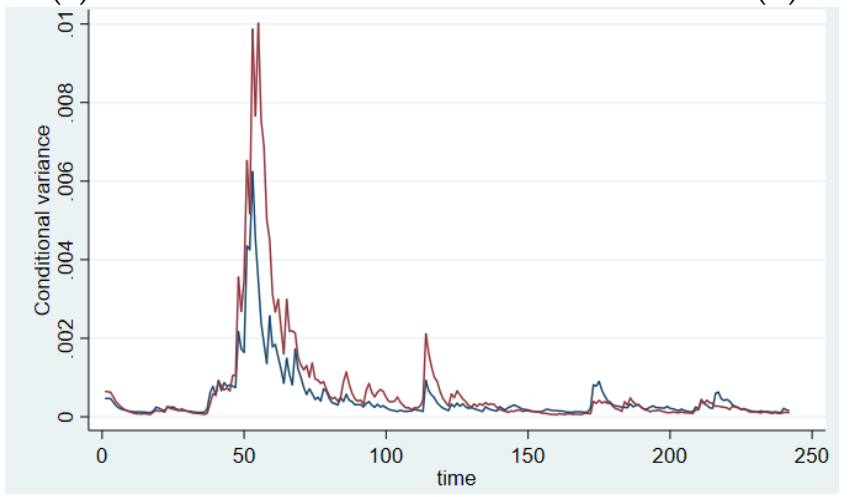

Overall NASDAQ, Top and Bottom 30\% CSR Stock Returns

(c)

Figure 1. (a) The returns of the top 30\% CSR stocks of the NASDAQ during 2020; (b) the returns of the top 30\% CSR stocks of the NASDAQ during 2020; (c) a line graph showing a comparison of the conditional variance of the top 30\% CSR stocks and bottom $30 \%$ CSR stocks.

\subsection{NASDAQ Sectors}

The same tests described above were performed for the top 30\% CSR stocks and bottom $30 \%$ CSR stocks of each sector. The sectors were tested to determine if the GARCH or EGARCH method were relevant enough to predict the volatility of that sector. The majority of the sectors mirrored the results of the overall NASDAQ top 30\% and bottom $30 \%$ (all graphs for each sector are listed in the Appendix A). There were a few sectors for which the GARCH or EGARCH method was unable to predict an accurate variance. In order to avoid a repetitive analysis, below is the comparison of each sector's conditional variance and further explanation of sector performance (Table 2).

The table above is a numeric representation summarizing the market returns graph, conditional variance graph, and correlation between the conditional variance of the top and bottom CSR stocks in each sector. The Market Rise (\%) column shows the percent increase of each category's returns, specifically during the volatility clustering at the peak of the initial market reaction to COVID- 19. The Market Fall (\%) column represents the percent decrease of returns during the same volatility clustering. The Conditional Variance Peak represents the highest peak of the rate of volatility predicted as a result of a global crisis. The Volatility Correlation column represents the correlation of the rate of volatility between the top 30\% CSR stocks and the bottom 30\% CSR stocks. 
Table 2. A numerical summary of the highest rate of rise and fall of the market's response to COVID-19 quarantines, the peak of the conditional variance, and the volatility correlation of the conditional variance of the sectors of the NASDAQ.

\begin{tabular}{|c|c|c|c|c|}
\hline Sectors & Market Rise $(\%) \approx$ & Market Fall $(\%) \approx$ & Conditional Variance Peak $\approx$ & Volatility Correlation \\
\hline \multicolumn{5}{|l|}{ Basic Materials } \\
\hline Top 30\% CSR & $\mathrm{N} / \mathrm{A}$ & $\mathrm{N} / \mathrm{A}$ & $\mathrm{N} / \mathrm{A}$ & $\mathrm{N} / \mathrm{A}$ \\
\hline Bottom $30 \%$ CSR & $15 \%$ & $-7 \%$ & 0.005 & \\
\hline \multicolumn{5}{|l|}{ Consumer Goods } \\
\hline Top 30\% CSR & $6 \%$ & $-15 \%$ & 0.006 & 0.9062 \\
\hline Bottom 30\% CSR & $9 \%$ & $-14 \%$ & 0.011 & \\
\hline \multicolumn{5}{|l|}{ Consumer Services } \\
\hline Top 30\% CSR & $15 \%$ & $-15 \%$ & 0.011 & 0.8769 \\
\hline Bottom 30\% CSR & $15 \%$ & $-21 \%$ & 0.030 & \\
\hline \multicolumn{5}{|l|}{ Financials } \\
\hline Top 30\% CSR & $11 \%$ & $-14 \%$ & 0.007 & 0.8744 \\
\hline Bottom 30\% CSR & $10 \%$ & $-14 \%$ & 0.009 & \\
\hline \multicolumn{5}{|l|}{ Health Care } \\
\hline Top 30\% CSR & $9 \%$ & $-10 \%$ & 0.005 & 0.9255 \\
\hline Bottom 30\% CSR & $7 \%$ & $-16 \%$ & 0.009 & \\
\hline \multicolumn{5}{|l|}{ Industrials } \\
\hline Top 30\% CSR & $7 \%$ & $-13 \%$ & 0.007 & 0.9538 \\
\hline Bottom 30\% CSR & $13 \%$ & $-16 \%$ & 0.013 & \\
\hline \multicolumn{5}{|l|}{ Energy } \\
\hline Top 30\% CSR & $10 \%$ & $-28 \%$ & $\mathrm{~N} / \mathrm{A}$ & $\mathrm{N} / \mathrm{A}$ \\
\hline Bottom 30\% CSR & $20 \%$ & $-38 \%$ & 0.05 & \\
\hline \multicolumn{5}{|l|}{ Technology } \\
\hline Top 30\% CSR & $10 \%$ & $-14 \%$ & 0.009 & 0.9679 \\
\hline Bottom 30\% CSR & $8 \%$ & $-10 \%$ & 0.005 & \\
\hline \multicolumn{5}{|c|}{ Telecommunications } \\
\hline Top 30\% CSR & $8 \%$ & $-12 \%$ & 0.007 & 0.9221 \\
\hline Bottom 30\% CSR & $10 \%$ & $-14 \%$ & 0.009 & \\
\hline \multicolumn{5}{|l|}{ Utilities } \\
\hline Top 30\% CSR & $12 \%$ & $-11 \%$ & 0.007 & 0.9221 \\
\hline Bottom $30 \%$ CSR & $11 \%$ & $-18 \%$ & 0.009 & \\
\hline
\end{tabular}

There is no comparison between the bottom 30\% and the top 30\% of CSR stocks in Basic Materials. In Consumer Goods, the bottom 30\% CSR stocks have a better performance of returns than the top 30\%. The top 30\% CSR stocks hit a lower peak at a 6\% increase during the first volatility clustering and had a high drop in returns at $15 \%$. The returns of Consumer Services have the same rate of rise in returns, and the bottom 30\% of CSR stocks drops lower at $-21 \%$. Both categories for Financials dropped at the same rate, but the top 30\% CSR stocks (11\%) slightly outperformed the bottom 30\% CSR stocks (10\%). The top 30\% CSR stocks for Health Care rose 9\% and dropped -10\%. The bottom 30\% CSR stocks for Health Care did not perform as well during the volatility cluster, rising $7 \%$ and dropping - 16\%. Industrials, Energy, and Telecommunications all have the same comparison results, where the top 30\% CSR stocks have a lower rise in returns and a lower drop in returns. The rise in returns in Technology for the top 30\% CSR stocks and bottom 
stocks are $10 \%$ and $8 \%$, and the drop in returns are $-14 \%$ and $-10 \%$, respectively. Finally, Utilities has the same result as Health, where the top 30\% CSR stocks perform better in the rise of returns as well as in the drop.

The conditional variance of each sector is a more thorough indicator of market volatility during a global crisis. The volatility for the bottom 30\% CSR stocks in Basic Materials peaks at 0.005 , as a market response to a global crisis. The rate of volatility clustering for Consumer Goods during the initial reaction of a crisis at 0.006 is lower compared to the bottom 30\% CSR stocks at 0.011 . For Consumer Services, the rate of volatility clustering is higher for the bottom 30\% CSR stocks at 0.03 , while the top 30\% CSR stock has a rate of 0.01 . The top 30\% CSR stocks in Financials have a more stable rate of volatility at 0.007 compared to the bottom at 0.009. Health Care, Industrials, Telecommunications, and Utilities all follow the same pattern as Financials, with the top 30\% CSR stocks being more stable than the bottom 30\% CSR stocks. Technology is the only sector that has the opposite results. The top 30\% CSR stocks are less stable than the bottom stocks at 0.009 and 0.005 , respectively. The rate of returns for Energy cannot determine the top 30\% of CSR stocks' conditional variance using the GARCH or EGARCH model. The mean of the variance was not normally distributed, making GARCH models insufficient. For the majority of sectors, the top 30\% CSR stocks are more stable during a crisis.

The graphs of each sector all have the same basic pattern of the overall NASDAQ with small variations. However, every graph shows a rapid peak in volatility as a reaction to a global crisis, with a slight decrease as time goes on during the crisis. As previously mentioned, there is no data available to test the top 30\% CSR stocks in Basic Materials. This makes it impossible to compare volatility performance. Neither the GARCH model nor the EGARCH model was able to accurately predict the conditional variance of the top 30\% CSR stocks for Energy. Results show that the top 30\% outperform in a major manner in the Health and Utilities sectors, where the increase in returns is larger and the drop in returns is lower. We hypothesize that the current pandemic situation affected consumers' and investors' preferences towards perceived higher quality Health and Utility services and therefore the top 30\% stocks showed a more sustainable performance and higher returns [17].

Technology together with Consumer Goods are the sectors whose top 30\% companies experienced a larger initial drop in returns. The initial larger drop of returns for the top $30 \%$ companies in the technological sector is hypothesized to take place because of the higher uncertainty associated with some of the cutting-edge goods and services offered by these leading companies. In the case of the sector of Consumer Goods, the top 30\% experienced just a $1 \%$ larger drop in returns than the bottom $30 \%$. Hence, the initial drop is quite even, $-15 \%$ for the top $30 \%$ and $-14 \%$ for the bottom $30 \%$. Following the economic theory, we assume that consumer goods that are not considered basic goods, or which price and income elasticity of demand are more inelastic, will continue to be bought. We assume that both the top 30\% and the bottom 30\% companies sell basic goods as well as goods that satisfy consumers' wants. We hypothesize that the top 30\% have a slightly relatively larger portfolio of goods whose elasticity of demand is relatively more elastic and hence the slightly larger $1 \%$ drop in returns.

Technology is the only sector where the conditional variance of the top $30 \%$ CSR stocks is 0.04 above the conditional variance of the bottom CSR stocks. We hypothesize that the reason for this is because the top 30\% have a larger portfolio of cutting-edge products and services than the bottom $30 \%$ and the foreseen marketability of some of these products and services was more uncertain than the marketability of the less cutting-edge products and services offered the bottom 30\% [41]. As a result, the initial market response to the pandemic rewarded more the cutting-edge products and services of the top $30 \%$ that were widely demanded and penalized the return of some of these top 30\% cutting-edge products and services that were assessed as non-marketable.

For all sectors, the correlations between the top and bottom CSR stocks are positive and significant. All correlations are above $80 \%$, indicating that the top $30 \%$ and bottom $30 \%$ CSR stocks in each sector move together, with only a slight difference in movement. 


\section{Conclusions}

There is a growing demand for sustainable business practices and for sustainable and impact investments as it has been signaled by the Sustainable Development Goals ratified by all the United Nations members. The empirical analysis results indicate that the top $30 \%$ CSR stocks within the NASDAQ marginally outperform the bottom 30\% CSR stocks in terms of volatility. When there is a market reaction to a global crisis, the volatility of the bottom 30\% CSR stocks increases at a higher rate than the top 30\% of CSR stocks. Under the assumption that volatility is a reflection of market uncertainty, there is more certainty in the top 30\% CSR stocks. For all sections except Technology, Basic Materials, and Energy, the top $30 \%$ is less volatile than the bottom 30\% CSR stocks. Basic Materials and Energy lack sufficient data to use either variation of the GARCH method to test for volatility clustering. Technology has data that allows for the testing of volatility. It is the only sector within the NASDAQ where the top 30\% CSR stocks have a higher volatility rate. Also, Technology and Consumer Goods are the only sectors that have a larger initial drop in returns for the top 30\% CSR stocks. The rise in returns varies between the sectors. Health and Utilities are the sectors where the top 30\% outperform the bottom 30\% the most, with a higher increase in returns and a lower drop in returns. While there are multiple potential reasons stocks with higher CSR ratings are less volatile, one of those reasons can be attributed to the fact that businesses with better sustainable practices have lower idiosyncratic risk and lower overall risk [17]. Sustainable investing benefits societies and the environment and even allows for a marginally more stable market. Another potential contribution to the lower rate of volatility is investor biases towards sustainable stocks [42]. The lower rate of conditional variance in the top 30\% CSR stocks shows there is more investor confidence in the companies with sustainable practices. Depending on the amount invested, the marginal difference in volatility could be a significant difference in the returns on an asset for the average investor [43].

There is limited information on sustainable stocks at this time. Sustainable investing still has a lot of unrealized potential in the market, and further analysis is necessary to determine the financial performance of sustainable stocks [44]. CSRHub, Inc. did not have rankings for all stocks in the NASDAQ. Those businesses with limited information on their sustainable practices are not rated. So there is the possibility that there were stocks that should have been included in either category. Also, the rankings are based on a collection of multiple sources. There is limited transparency from companies about their sustainable practices. The primary focus of this paper is to determine sustainable investments during a global pandemic. There is limited information on sustainable stock performances during a different form of crisis. Further research on sustainable stocks is necessary [45].

Large financial firms are beginning to include sustainable analysis in their portfolio analysis, but there is limited information for smaller investors to also invest sustainably. Popular financial sites, like Yahoo Finance, do not have a sustainability metric the way they represent CAPM (Capital Asset Pricing Model), book per price ratios, or other financial metrics. Sustainable investing helps create a better society and reduces the negative impacts on the environment. Sustainability is increasing in popularity. There is still a lot of research necessary before creating the standard for this type of analysis. However, there is growing evidence that a sustainable metric for portfolio analysis can help create a more successful portfolio [46,47].

Author Contributions: All authors contributed equally to the conceptualization, methodology, software, validation, data analysis and execution, writing — review and editing, visualization, and supervision of this paper at all stages. All authors have read and agreed to the published version of the manuscript.

Funding: This research received funding from Geneva Business School.

Institutional Review Board Statement: Not applicable.

Informed Consent Statement: Not applicable. 
Data Availability Statement: Not applicable.

Conflicts of Interest: The authors declare no conflict of interest.

\section{Appendix A}

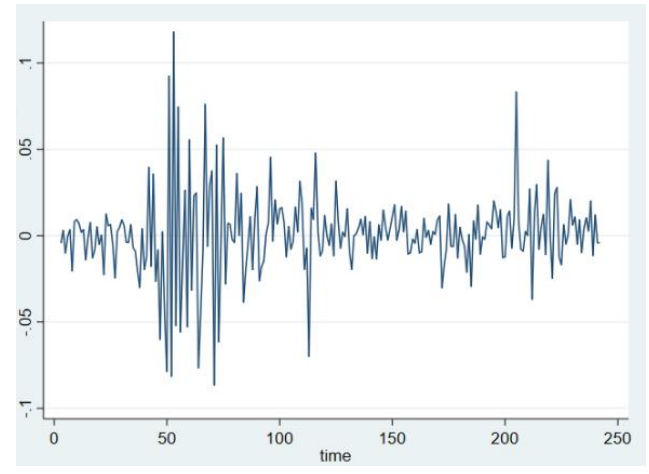

Bottom 30\% CSR Stock Returns, Basic Materials (a)

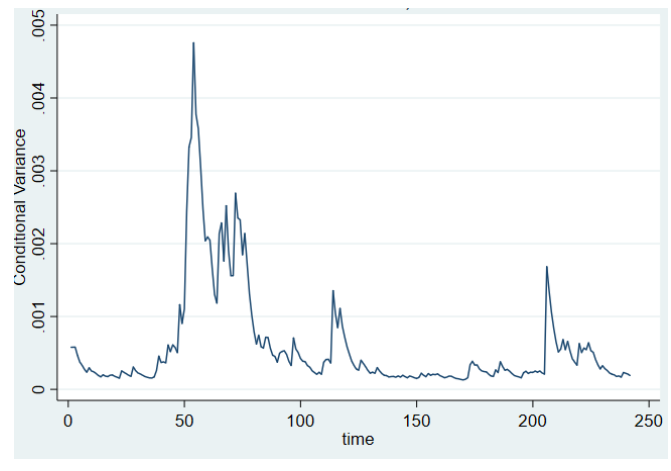

Bottom 30\% CSR Stock Basic Materials, Conditional Covariance over time (b)

Figure A1. (a) The returns for the bottom 30\% CSR stocks in Basic Materials during 2020; (b) the conditional variance of the bottom 30\% CSR stocks in Basic Materials.

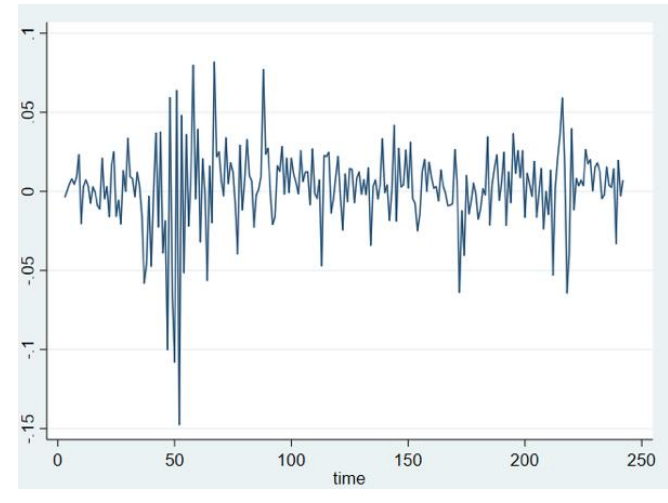

Top 30\% CSR Stock Returns, Consumer Goods

(a)

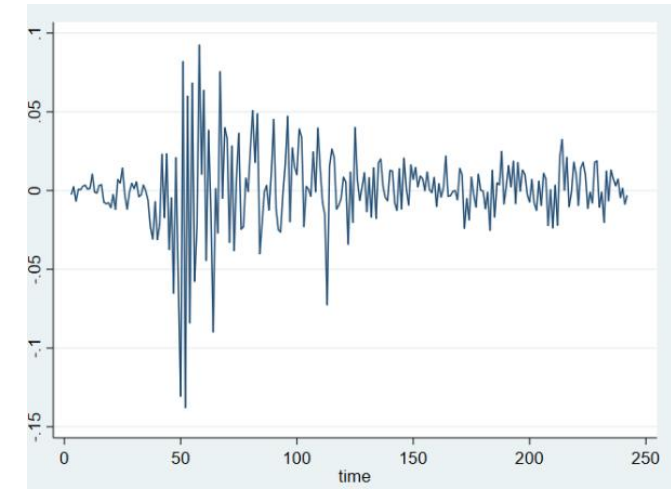

Bottom 30\% CSR Stock Returns, Consumer Goods

(b)

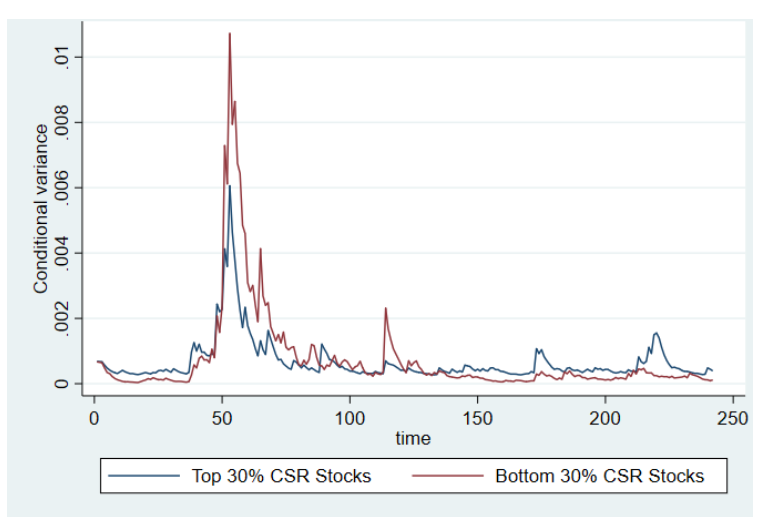

Top and Bottom 30\% CSR Stock Returns, Consumer Goods

(c)

Figure A2. (a) The returns of the top 30\% CSR stocks in Consumer Goods during 2020; (b) the returns of the bottom 30\% CSR stocks in Consumer Goods during 2020; (c) a line graph showing a comparison of the conditional variance of the top $30 \%$ CSR stocks and bottom 30\% CSR stocks in Consumer Goods. 


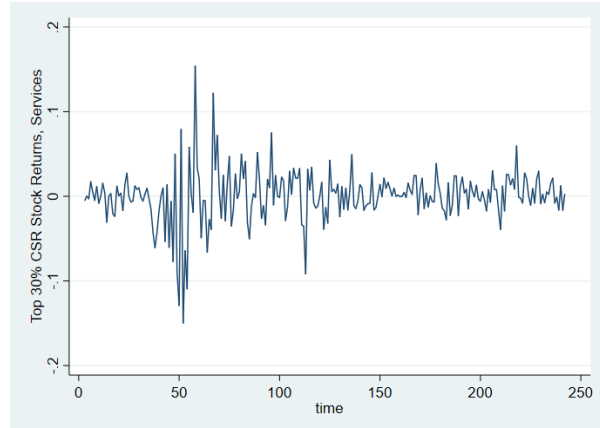

Top 30\% CSR Stock Returns, Services

(a)

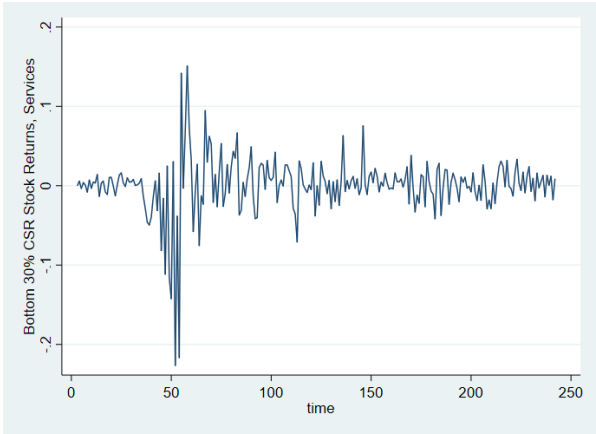

Bottom 30\% CSR Stock Returns, Services

(b)

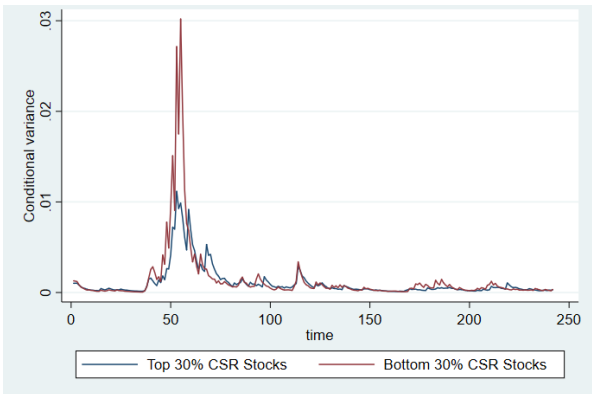

Top and Bottom 30\% CSR Stock Returns, Services

(c)

Figure A3. (a) The returns of the top 30\% CSR stocks in Consumer Services during 2020; (b) the returns of the bottom 30\% CSR stocks in Consumer Services during 2020; (c) a line graph showing a comparison of the conditional variance of the top $30 \%$ CSR stocks and bottom 30\% CSR stocks in Consumer Services.

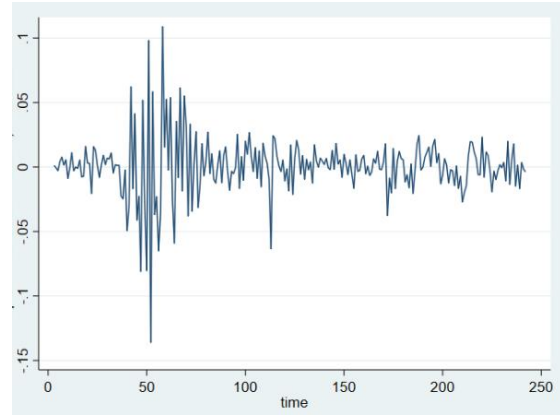

Top 30\% CSR Stock Returns, Financials

(a)

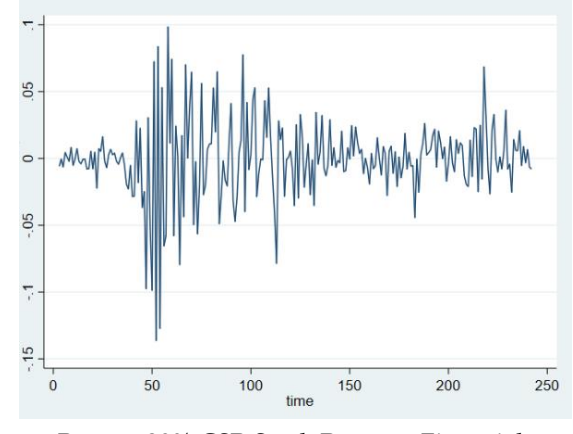

Bottom 30\% CSR Stock Returns, Financials

(b)

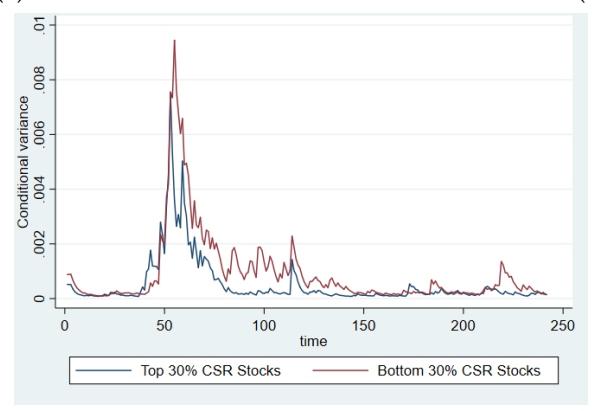

Top and Bottom 30\% CSR Stock Returns, Financials

(c)

Figure A4. (a) The returns of the top 30\% CSR stocks in Financials during 2020; (b) the returns of the bottom 30\% CSR stocks in Financials during 2020; (c) a line graph showing a comparison of the conditional variance of the top 30\% CSR stocks and bottom 30\% CSR stocks in Financials. 


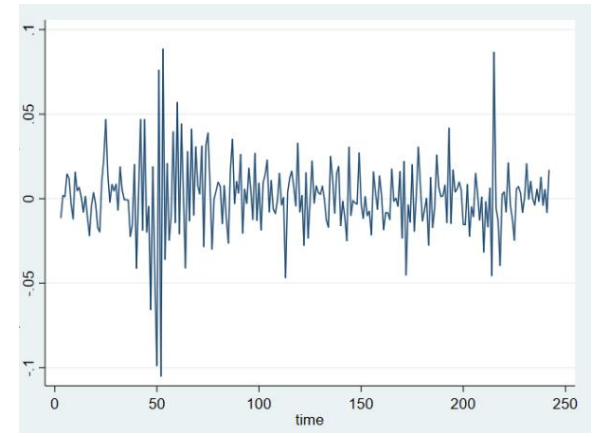

Top 30\% CSR Stock Returns, Health Care

(a)

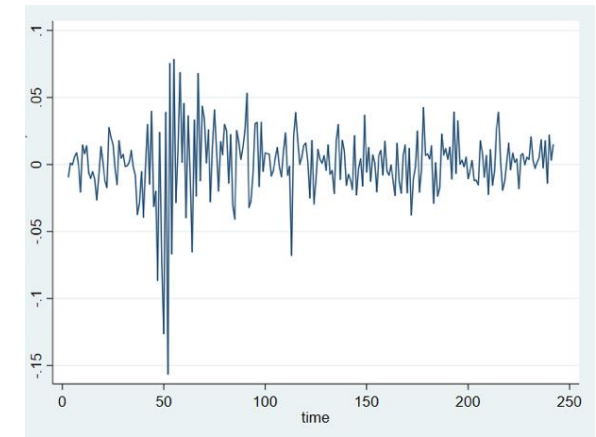

Bottom 30\% CSR Stock Returns, Health Care

(b)

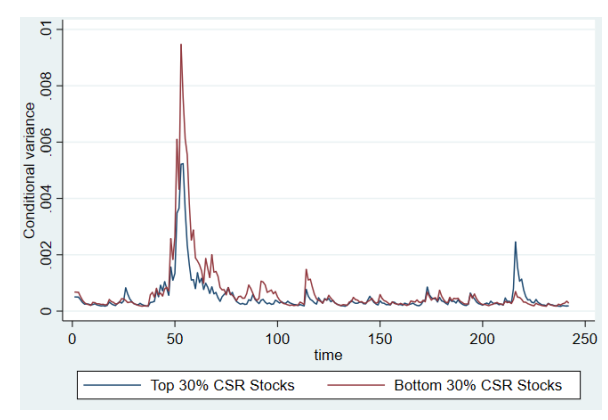

Top and Bottom 30\% CSR Stock Returns Health Care

(c)

Figure A5. (a) The returns of the top 30\% CSR stocks in Health Care during 2020; (b) the returns of the bottom 30\% CSR stocks in Health Care during 2020; (c) a line graph showing a comparison of the conditional variance of the top 30\% CSR stocks and bottom 30\% CSR stocks in Health Care.

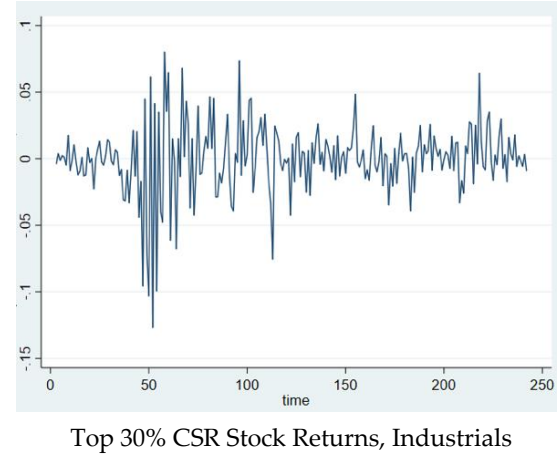

(a)

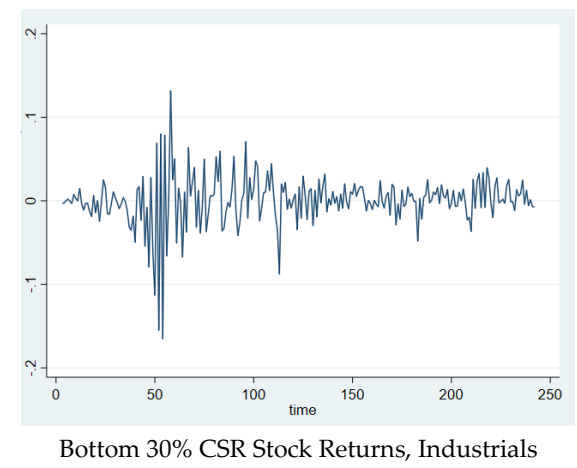

(b)

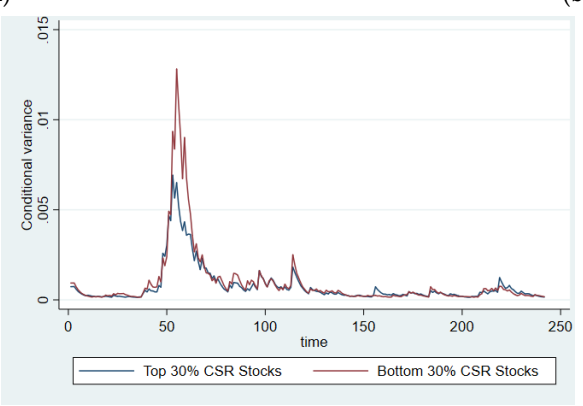

Top and Bottom 30\% CSR Stock Returns Industrials

(c)

Figure A6. (a) The returns of the top 30\% CSR stocks in Industrials during 2020; (b) the returns of the bottom 30\% CSR stocks in Industrials during 2020; (c) a line graph showing a comparison of the conditional variance of the top 30\% CSR stocks and bottom $30 \%$ CSR stocks in Industrials. 


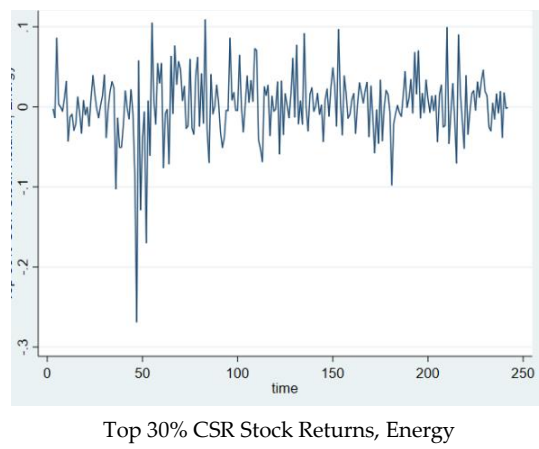

(a)

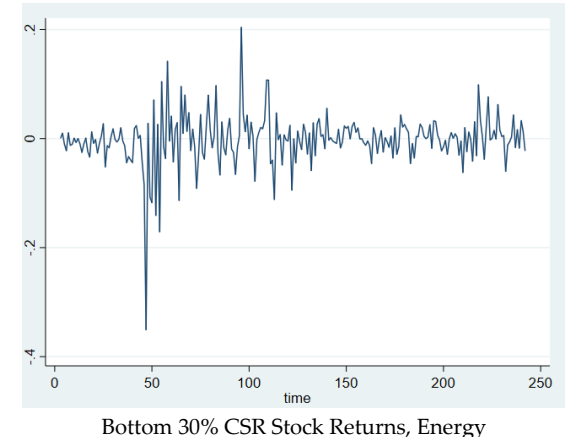

(b)

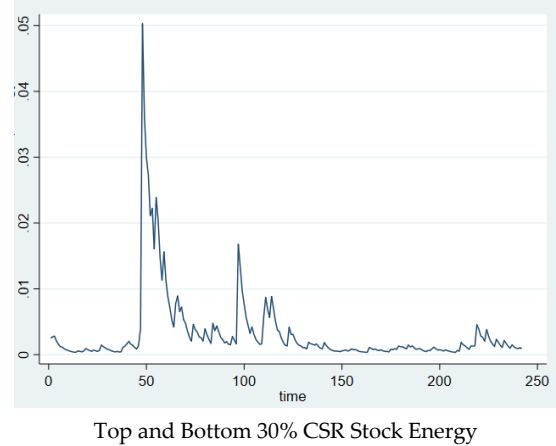

(c)

Figure A7. (a) The returns of the top 30\% CSR stocks in Energy during 2020; (b) the returns of the top 30\% CSR stocks in Energy during 2020; (c) a line graph showing a comparison of the conditional variance of the bottom 30\% CSR stocks in Energy.

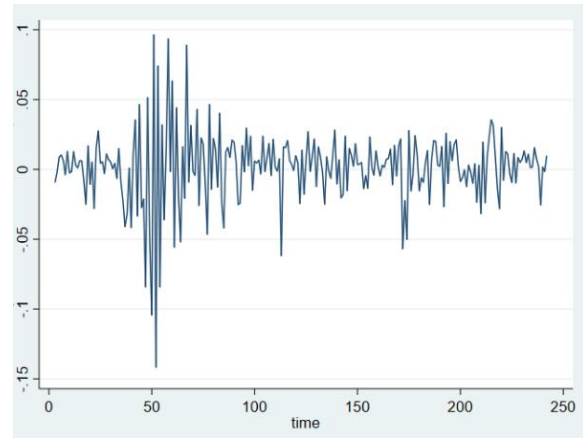

Top 30\% CSR Stock Returns, Technology

(a)

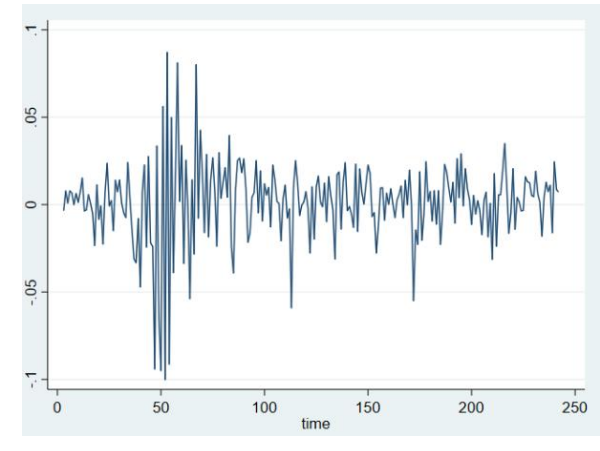

Top 30\% CSR Stock Returns, Technology

(b)

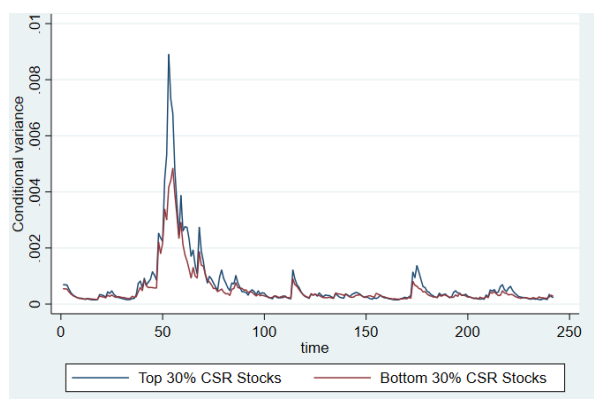

Top and Bottom 30\% CSR Stock Returns, Technology

(c)

Figure A8. (a) The returns of the top 30\% CSR stocks in Technology during 2020; (b) the returns of the bottom 30\% CSR stocks in Technology during 2020; (c) a line graph showing a comparison of the conditional variance of the top 30\% CSR stocks and bottom $30 \%$ CSR stocks in Technology. 


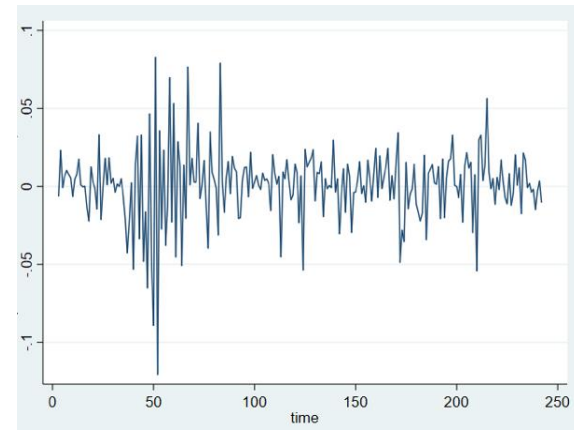

Top 30\% CSR Stock Returns, Telecommunications

(a)

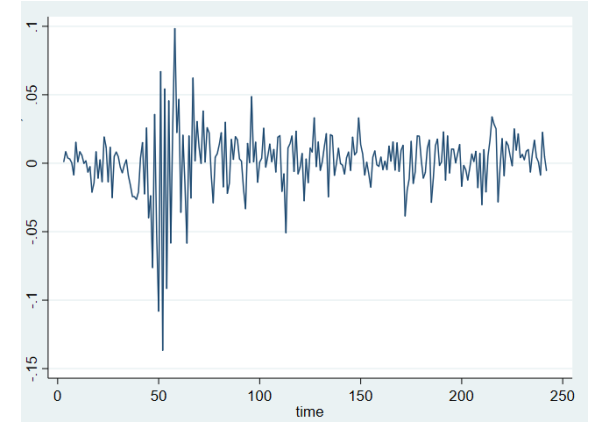

Bottom 30\% CSR Stock Returns, Telecommunications

(b)

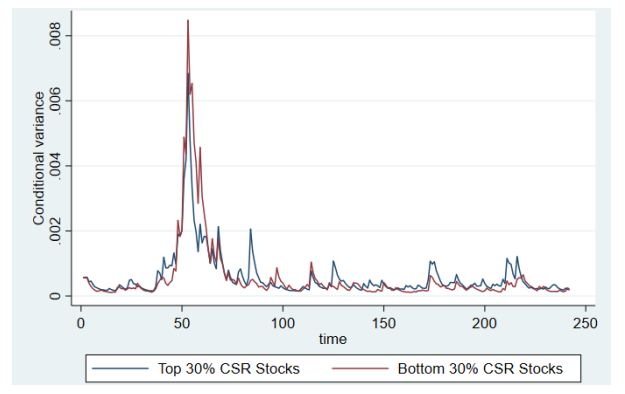

Top and Bottom 30\% CSR Stock Returns, Telecommunications

(c)

Figure A9. (a) The returns of the top 30\% CSR stocks in Telecommunications during 2020; (b) the returns of the bottom 30\% CSR stocks in Telecommunications during 2020; (c) a line graph showing a comparison of the conditional variance of the top $30 \%$ CSR stocks and bottom 30\% CSR stocks in Telecommunications.

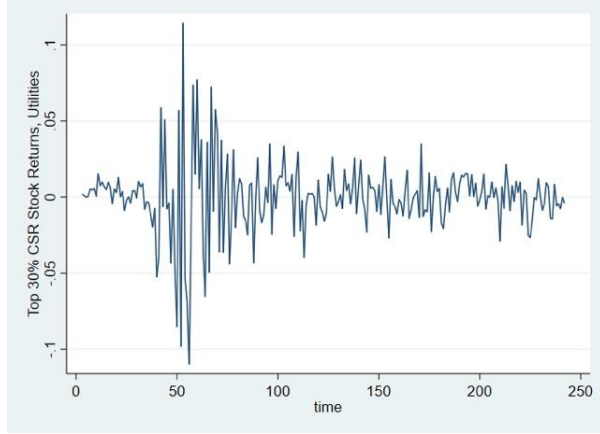

Top 30\% CSR Stock Returns, Utilities

(a)

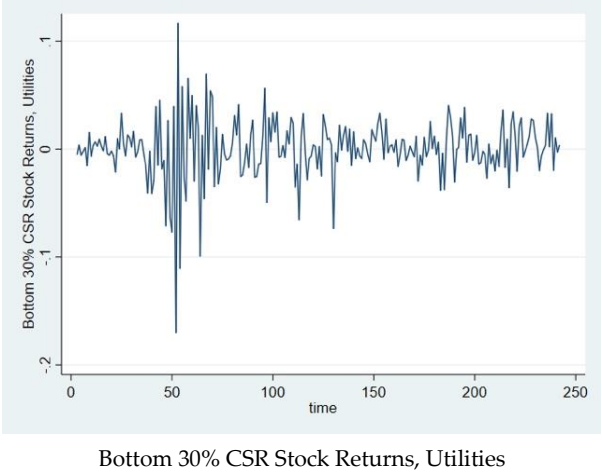

(b)

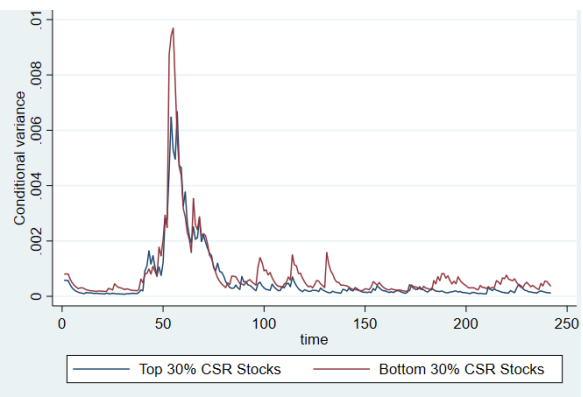

Top and Bottom 30\% CSR Stock Returns, Utilities

(c)

Figure A10. (a) The returns of the top 30\% CSR stocks in Utilities during 2020; (b) the returns of the bottom 30\% CSR stocks in Utilities during 2020; (c) a line graph showing a comparison of the conditional variance of the top 30\% CSR stocks and bottom 30\% CSR stocks in Utilities. 


\section{References}

1. Cucinotta, D.; Vanelli, M. WHO declares COVID-19 a pandemic. Acta Bio. Med. Atenei Parm. 2020, 91, 157-160.

2. Lee, A. Wuhan novel coronavirus (COVID-19): Why global control is challenging? Public Health 2020, 179, A1-A2. [CrossRef] [PubMed]

3. Bagchi, B.; Chatterjee, S.; Ghosh, R.; Dandapat, D. Impact of COVID-19 on Global Economy. In Coronavirus Outbreak Great Lockdown; Springer: Singapore, 2020; pp. 15-26.

4. Pyatanova, V.I.; Pyatanov, I.A. Responsible finance: Application and challenges for society, governments and corporations. Управление 2020, 8, 57-62. [CrossRef]

5. Albitar, K.; Hussainey, K.; Kolade, N.; Gerged, A.M. ESG disclosure and firm performance before and after IR: The moderating role of governance mechanisms. Int. J. Account. Inf. Manag. 2020, 28, 429-444.

6. Bugg-Levine, A.; Emerson, J. Impact investing: Transforming how we make money while making a difference. Innov. Technol. Gov. Glob. 2011, 6, 9-18.

7. Koundouri, P. Never Waste a Good Crisis: For a Sustainable Recovery from COVID-19; Sustainable Development Solutions Network: Athens, Greece, 2020.

8. Mai, V.P.N. Are You Truly Sustainable? An Investigation of the Main Features of De-Certified B-Corps. Master's Thesis, University Degli Studi di Padova, Padua, Italy, 2020.

9. Hyndman, R.J. CRAN Task View: Time Series Analysis. Available online: https://cran.r-project.org/web/views/TimeSeries.html (accessed on 15 March 2020).

10. Hale, T.; Petherick, A.; Phillips, T.; Webster, S. Variation in Government Responses to COVID-19; Blavatnik School of Government Working Paper; 2020; Volume 31.

11. Barrero, J.M.; Bloom, N.; Davis, S.J. Covid-19 Is also a Reallocation Shock (No. w27137); National Bureau of Economic Research: Chicago, UK, 2020.

12. Mei, J.; Guo, L. Political uncertainty, financial crisis and market volatility. Eur. Financ. Manag. 2004, 10, 639-657. [CrossRef]

13. Ellina, P.; Mascarenhas, B.; Theodossiou, P. Clarifying managerial biases using a probabilistic framework. J. Behav. Exp. Financ. 2020, 27, 100333. [CrossRef]

14. Baker, S.R.; Bloom, N.; Davis, S.J.; Kost, K.J.; Sammon, M.C.; Viratyosin, T. The Unprecedented Stock Market Impact of COVID-19 (No. w26945); National Bureau of Economic Research: Cambridge, MA, USA, 2020.

15. Baek, S.; Mohanty, S.K.; Glambosky, M. COVID-19 and stock market volatility: An industry level analysis. Financ. Res. Lett. 2020, 37, 101748. [CrossRef]

16. Goodell, J.W. COVID-19 and finance: Agendas for future research. Financ. Res. Lett. 2020, 35, 101512. [CrossRef]

17. Sassen, R.; Hinze, A.K.; Hardeck, I. Impact of ESG factors on firm risk in Europe. J. Bus. Econ. 2016, 86, 867-904. [CrossRef]

18. Fisch, J.E. Making sustainability disclosure sustainable. Georget. Law J. 2018, 107, 923.

19. Fleming, R.A.; Ledbetter, A.M. Making Mandatory Sustainability Disclosure a Reality. Envtl. L. Rep. 2020, $50,10647$.

20. Voegtlin, C.; Pless, N.M. Global governance: CSR and the role of the UN Global Compact. J. Bus. Ethics 2014, 122, 179-191. [CrossRef]

21. Schaltegger, S.; Burritt, R. Business cases and corporate engagement with sustainability: Differentiating ethical motivations. J. Bus. Ethics 2018, 147, 241-259. [CrossRef]

22. Yoshino, N.; Taghizadeh-Hesary, F.; Otsuka, M. Covid-19 and optimal portfolio selection for investment in sustainable development goals. Financ. Res. Lett. 2021, 38, 101695.

23. Marjan, M.N. The Effect of ICT Investment ICT Governance Mechanisms, Boards with Diverse ICT Expertise and Ownership Structures on Firm Performance. Ph.D. Thesis, Universiti Utara, Changlun, Malaysia, 2020.

24. Alessandrini, F.; Jondeau, E. ESG investing: From sin stocks to smart beta. J. Portf. Manag. 2020, 46, 75-94. [CrossRef]

25. Nabipour, M.; Nayyeri, P.; Jabani, H.; Shahab, S.; Mosavi, A. Predicting Stock Market Trends Using Machine Learning and Deep Learning Algorithms Via Continuous and Binary Data; a Comparative Analysis. IEEE Access 2020, 8, 150199-150212. [CrossRef]

26. Engle, R. GARCH 101: The use of ARCH/GARCH models in applied econometrics. J. Econ. Perspect. 2001, 15, 157-168. [CrossRef]

27. Yilmaz, M.K.; Aksoy, M.; Tatoglu, E. Does the stock market value inclusion in a sustainability index? Evidence from Borsa Istanbul. Sustainability 2020, 12, 483. [CrossRef]

28. StataCorp LLC. STATA Finite Mixture Models Reference Manual; StataCorp LLC: College Station, TX, USA, 2017.

29. Bakanauskienė, I.; Bendaravičienė, R.; Juodelytė, N.; Vveinhardt, J. Sustainability of Nasdaq-listed companies: The effects of participation in the UNGC. Pol. J. Manag. Stud. 2020, 21, 87-103. [CrossRef]

30. Fama, E.F.; French, K.R. Size and book-to-market factors in earnings and returns. J. Financ. 1995, 50, 131-155. [CrossRef]

31. CSRHUB. Data Sustainability Management Tools Sample Demo. Available online: https://www.csrhub.com/subscription_ sample/\#rating-section (accessed on 13 March 2020).

32. McKnight, S. Statistical Analysis for Financial Data: A Case Study of Four Stocks. Ph.D. Thesis, Montana State University, Bozeman, Montana, 2019.

33. Neusser, K. Time Series Econometrics, 1st ed.; Springer International Publication: Cham, Switzerland, 2016; pp. 134-196.

34. Hansen, P.R.; Lunde, A. A forecast comparison of volatility models: Does anything beat a GARCH (1, 1)? J. Appl. Econom. 2005, 20, 873-889. [CrossRef] 
35. Bollerslev, T.; Engle, R.F.; Nelson, D.B. ARCH models. In Handbook of Econometrics; Duke University: Durham, NC, USA, 1994; Volume 4, pp. 2959-3038.

36. Siemes, I. Consumer Sentiment and its Power in Predicting Economic Success. Ph.D. Thesis, Tilburg University, Tilburg, The Netherlands, 2019.

37. Hyndman, R.J. Time Series Analysis, 1st ed.; CRAN Task View International Publication: Morton Grove, IL, USA, 2021.

38. Dicle, M.F.; Levendis, J. Importing financial data. Stata J. 2011, 11, 620-626. [CrossRef]

39. Hilmola, O.P. Stock market performance and manufacturing capability of the fifth long-cycle industries. Futures 2007, 39, 393-407. [CrossRef]

40. Broadstock, D.C.; Chan, K.; Cheng, L.T.; Wang, X. The role of ESG performance during times of financial crisis: Evidence from COVID-19 in China. Financ. Res. Lett. 2021, 38, 101716. [CrossRef] [PubMed]

41. Taffler, R. Emotional finance: Investment and the unconscious. Eur. J. Financ. 2018, 24, 630-653. [CrossRef]

42. Philipson, S. Consumers and enterprises as actors on the market. Harv. Deusto Bus. Res. 2020, 9, 168-180. [CrossRef]

43. Cuñado, J.H.; Díez, J.C.; Román, J.A.E. Engie: Business Model Transformation. Harv. Deusto Bus. Res. 2020, 9, $152-167$.

44. Spallini, S.; Milone, V.; Nisio, A.; Romanazzi, P. The Dimension of Sustainability: A Comparative Analysis of Broadness of Information in Italian Companies. Sustainability 2021, 13, 1457. [CrossRef]

45. Ang, A.; Hodrick, R.J.; Xing, Y.; Zhang, X. The cross-section of volatility and expected returns. J. Financ. 2006, 61, 259-299. [CrossRef]

46. Dennis, P.; Mayhew, S.; Stivers, C. Stock returns, implied volatility innovations, and the asymmetric volatility phenomenon. J. Financ. Quant. Anal. 2006, 41, 381-406. [CrossRef]

47. Lumley, T.; Scott, A. AIC and BIC for modeling with complex survey data. J. Surv. Stat. Methodol. 2015, 3, 1-18. [CrossRef] 